JHR

36,1

140

Received 18 March 2020 Revised 3 May 2020 17 May 2020

Accepted 25 May 2020

\section{Utilization of maternal health services in rural Thawang, Rolpa district of Nepal: a community- based cross-sectional study}

\author{
Jahirul Hushen \\ Faculty of Public Health, Mahidol University, Rajvithi Campus, Bangkok, Thailand \\ Arpaporn Powwattana \\ Department of Public Health Nursing, Mahidol University, Rajvithi Campus, \\ Bangkok, Thailand \\ Chockchai Munsawaengsub \\ Department of Family Health, Mahidol University, Rajuithi Campus, \\ Bangkok, Thailand, and \\ Sukhontha Siri \\ Department of Epidemiology, Mahidol University, Rajvithi Campus, \\ Bangkok, Thailand
}

\begin{abstract}
Purpose - This study aimed to identify the proportion and factors influencing the use of maternal health services (MHS) in rural Thawang, Rolpa, Nepal.

Design/methodology/approach - This was a community-based cross-sectional study conducted among 417 mothers who had given birth in the previous two years. Bivariate and multivariate logistic regression was applied to identify associations and predictors.

Findings - The results showed that the use of maternal health services was $50.8 \%$. Adjusting for all other factors in the final model, age group 25-30 years (AOR: 2.30; 95\% CI: 1.199-4.422), spouse communication (AOR: 7.31; 95\% CI: 2.574-20.791), high accessibility (AOR: 2.552, 95\% CI: 1.402-4.643) and high affordability (AOR: 10.89; 95\% CI: 4.66-25.445) were significant predictors.

Research limitations/implications - This is a community-based cross-sectional study, and hence cannot establish causal relationships. The research was conducted in a limited rural area mid-Western Nepal, and this may limit the generalization of results to other settings of the country.

Practical implications - This research supports to local level government and district health authority to develop and implement need based action to increase maternal health service in the local context.

Originality/value - Underutilization of maternal health services is the result of socioeconomic dynamics, poor access to health services and other physical developments. To increase utilization of maternal health services in rural areas, there is a need to tackle the root cause of health inequality such as reducing poverty, increasing female education, involving women in employment and increasing access to health as a priority development agenda by government authorities. This research supports local level government and district health authorities to develop and implement needs-based action to increase MHS in the local context.
\end{abstract}

Keywords ANC visit, Service access, Maternal health service utilization, Women's autonomy, Nepal Paper type Research paper

\footnotetext{
(C) Jahirul Hushen, Arpaporn Powwattana, Chockchai Munsawaengsub and Sukhontha Siri. Published in Journal of Health Research. Published by Emerald Publishing Limited. This article is published under the Creative Commons Attribution (CC BY 4.0) licence. Anyone may reproduce, distribute, translate and create derivative works of this article (for both commercial and non-commercial purposes), subject to full attribution to the original publication and authors. The full terms of this licence may be seen at http:// creativecommons.org/licences/by/4.0/legalcode
}

Journal of Health Research Vol. 36 No. 1, 2022 pp. $140-149$

Emerald Publishing Limited e-ISSN: 2586-940X

DOI 10.1108/JHR-03-2020-0069 


\section{Introduction}

Globally, almost 830 women die every day from pregnancy or childbirth-related causes. In 2015, approximately 303,000 women died from pregnancy or childbirth-related causes [1]. Almost all of these deaths were preventable and were mostly recorded to be from developing countries [2]. Globally, between 1990 and 2015, the maternal mortality rate (MMR) dropped from 385 to 216 per 100,000 live births. However, developing countries accounted for approximately $99 \%$ of global deaths in 2015 [3]. Nepal has made significant progress to reduce MMR in the past but still has the highest rate (258/100,000 live birth in 2015) in the South Asian region except for Afghanistan $[4,5]$. Nepal has set a target to reduce MMR to less than 70 per 100,000 live births by 2030 [6]. Underutilization of maternal health services (MHS) in Nepal may be one of the important factors for maternal deaths. $11 \%$ of deaths in Nepal are related to maternal death with $40 \%$ of maternal deaths occurring in the home [7]. Antenatal care visits and quality health services are essential strategies to reduce maternal morbidity and mortality, [8,9] as it can support the detection and treatment of complications, support with care and rest during the pregnancy, improve pregnancy outcome [10], and is effective in increasing institutional delivery (skilled birth attendance), which is effective in decreasing maternal mortality in developing countries [1, 11].

To improve the health of women, the Nepali government has provided MHS including promoting birth preparedness, expansion of $24 \mathrm{~h}$ birthing facilities and expansion of $24 \mathrm{~h}$ emergency obstetric care services in selected health facilities [12]. Thus, the Nepal government and local level authority has added new birthing centers within health facilities and outreach clinics in hard to reach areas, to increase the use of MHS [12]. These are guided by a national reproductive health strategy (1998), and skilled birth attendant policy (2006) [13]. Additionally, in 2009, the "Aaama surkchya program" was launched to ensure free service for ANC visits and institutional delivery. To engage and promote community health, community-based programs such as female community health volunteers (FCHV) and community-based integrated management of neonatal and child health illness (CBIMNCI) programs have been organized to identify and counsel pregnant mothers and encourage them to utilize MHS [12].

Nepal has a complex socio-cultural and ethnic diversity. Socioeconomic, cultural values and norms, individuals, and the environment influence the use of MHS [14]. Nepal had just more than half $(52 \%)$ the prevalence of ANC visits as a recommendation in the Fiscal Year $2016 / 2017$, with a disparity in regions due to other socioeconomic factors. Rolpa district, the study site, is located in province number 5 (a hilly region) with ANC visits at $44 \%$ and institutional delivery at 50\%, and therefore, less than the national average in FY 2016/2017 $[12,15]$. In remote areas in particular, the proportionate use of MHS is relatively low.

Previous studies have attempted to explore the barriers to the use of MHS from sociodemographic, economic perspectives [16, 17], and others from sociocultural and belief perspectives $[18,19]$. Apart from the sociocultural and economic aspect, there were a growing number of studies emphasizing the role of women's access and affordability to health services [20-22]. However, the findings remain mixed. Based on previous study outcomes, multiple aspects such as predisposing factors, women's autonomy and health access factors were selected for the study. Thus, this setting is particularly suitable for examining factors that influence or limit the use of MHS and aimed to derive lessons learned which may apply to districts and other stakeholders for planning. This research aimed to explore the influence of predisposing factors, women's autonomy and health service access on the utilization of MHS in rural Rolpa. For this research, Andersen's behavior model of health service use [23] and Zimmerman's theory of women's autonomy [24] were used to construct the conceptual framework.

\section{Methods}

Study area

This research was carried out in the Thawang Rural Municipality of Rolpa district of Nepal, a remote and mostly conflicted area of Nepal due to 10 years of Maoist movement from 1996 to
Utilization of maternal health services 
JHR

36,1
2005. It ranks among the lowest categories of human development index (HDI) in the nation (below 0.40) [25] with a total area of 1879 square $\mathrm{km}$. politically, the Rolpa district is divided into 9 rural municipalities (RM) and 1 main municipality. Thawang RM is situated in the northern part of the district, which is 28 kilometers away from district headquarter Liwang, with a total population of 224,506.

\section{Study design, study participants and sample size}

This was a community-based cross-sectional study with mothers who had given birth during the last two years prior to the data collection period between July 15, 2017 and July 14, 2019 (i.e., one week prior to the commencement of information collection).

The sample of mothers was selected from all five wards of Thawang's rural municipalities (RM). The sampling was done by a stratified random sampling method. First, all 5 wards were selected for the representation of all areas of Thawang with 613 total eligible respondents [15]. Second, each ward sample was calculated proportionally based on eligible respondents in each ward. Finally, at the ward level, the first mother was selected randomly based on information obtained from health facilities and then the remaining respondents were selected by systematic sampling.

The sample size for the research was calculated by using the sample size formula given in the book published by the World Health Organization named "adequacy of sample size in health studies," where the prevalence is known and the margin of error was taken at $5 \%$ [26]. In this research, a $44 \%$ prevalence of utilization of recommended ANC visits in the last FY 2016/17 of Rolpa district [15] was used and the 5\% margin of error assuming a non-response rate of $10 \%$ meant that the final sample size was 417 .

\section{Data collection and instrument}

Data collection took place between July and November 2019. Before data collection, the health facilities of selected wards were visited and a list of mothers who had given birth between July 15, 2017 and July 14, 2019 were obtained.

Structured questions were used in this research. Questionnaires were developed by the researcher based on literature review and theory under the supervision of experts. For validation, questions were validated by three experts in family health, epidemiology and statistics and reliability tests were carried out among 30 respondents from outside the study site before finalizing the instrument. Initially, questions were prepared in English and translated into the Nepali language.

Data collection took place with three experienced and trained enumerators through face to face interviews with the mothers by visiting them in their homes. All three enumerators were bachelor's degree holders in sociology and allied health sciences. The first author provided them with two days of orientation about the study instrument and the objective of the research.

\section{Variables}

\section{Outcome variable}

This research considered maternal health service utilization as an outcome variable, assessed by an antenatal care visit (ANC visit) as a proxy indicator, based on the World Health Organization recommendations on ANC [27]. This was categorized into (1) No/Incomplete MHS utilization ( $\leq 3$ ANC visits or) and (2) use of MHS (Minimum 4 ANC visits as a recommendation).

\section{Study variables}

Seventeen variables were considered for the potential association with outcome variables, which were categorized into three groups (Table 1): 


\begin{tabular}{|c|c|c|c|}
\hline Variable & Frequency & Percent & Utilization of \\
\hline $\begin{array}{l}\text { Religion } \\
\text { Hindu } \\
\text { Other religion }\end{array}$ & $\begin{array}{r}324 \\
93\end{array}$ & $\begin{array}{l}77.7 \\
22.3\end{array}$ & health services \\
\hline $\begin{array}{l}\text { Caste and ethnicity } \\
\text { Upper caste } \\
\text { Janjati } \\
\text { Dalit }\end{array}$ & $\begin{array}{r}52 \\
271 \\
94\end{array}$ & $\begin{array}{l}12.5 \\
65.0 \\
22.5\end{array}$ & 143 \\
\hline $\begin{array}{l}\text { Age group of respondent } \\
<25 \text { years } \\
25-30 \text { years } \\
\geq 30 \text { years }\end{array}$ & $\begin{array}{l}209 \\
108 \\
100\end{array}$ & $\begin{array}{l}50.1 \\
25.9 \\
24.0\end{array}$ & \\
\hline $\begin{array}{l}\text { Education level of responder } \\
\text { Illiterate } \\
\text { Low level of education } \\
\text { Higher level of education }\end{array}$ & $\begin{array}{l}167 \\
117 \\
133\end{array}$ & $\begin{array}{l}40.0 \\
28.1 \\
31.9\end{array}$ & \\
\hline $\begin{array}{l}\text { Education level of husband } \\
\text { Illiterate } \\
\text { Low level of education } \\
\text { Higher level of education }\end{array}$ & $\begin{array}{r}230 \\
144 \\
43\end{array}$ & $\begin{array}{l}55.2 \\
34.5 \\
10.3\end{array}$ & \\
\hline $\begin{array}{l}\text { Occupation of the responder } \\
\text { Employed (self/service) } \\
\text { Daily worker } \\
\text { Housewife/Unemployed }\end{array}$ & $\begin{array}{r}59 \\
129 \\
229\end{array}$ & $\begin{array}{l}14.2 \\
30.9 \\
54.9\end{array}$ & \\
\hline $\begin{array}{l}\text { Occupation of husband } \\
\text { Employed (self/service) } \\
\text { Daily worker } \\
\text { Unemployed }\end{array}$ & $\begin{array}{r}114 \\
265 \\
38\end{array}$ & $\begin{array}{r}27.4 \\
63.5 \\
9.1\end{array}$ & \\
\hline $\begin{array}{l}\text { Family type } \\
\text { Nuclear } \\
\text { Joint }\end{array}$ & $\begin{array}{l}135 \\
282\end{array}$ & $\begin{array}{l}32.4 \\
67.6\end{array}$ & \\
\hline $\begin{array}{l}\text { Gender of household head } \\
\text { Male } \\
\text { Female }\end{array}$ & $\begin{array}{l}243 \\
174\end{array}$ & $\begin{array}{l}58.3 \\
41.7\end{array}$ & $\begin{array}{r}\text { Table 1. } \\
\text { Distribution of study } \\
\text { variables }\end{array}$ \\
\hline
\end{tabular}

(1) predisposing factors included religion (Hindu and other religions including Buddhist, Muslim, Kirat and Christian), caste/ethnicity (upper caste, janjati and dalit), age, education of respondents and details of husband's education (illiterate, low-level education, high-level education), occupation of the respondent and her husband (employed, daily worker and unemployed), family type (joint, nuclear), the gender of household head (male or female), household economic wealth index (measured into five subgroups: poorest, poorer, middle, richer and richest); were derived using principal component analysis based on information from housing characteristics and ownership of household durable goods), knowledge of maternal health (derived from correct information on danger signs during pregnancy and maternal health provision and services, categorized into low, moderate and high). 
JHR

36,1

144

(2) Women's autonomy included (1) Decision-making autonomy: included women's independence and participation at the household level decision-making processes such as seeking maternal health care, own marriage, household purchases for daily needs, and visiting relatives/friends. It was measured in three subgroups: low, moderate and high. (2) Financial control autonomy referred to women's independence in earning and decision making on own earning and livelihood and was measured in three subgroups low, moderate and high and (3) Spousal communication on maternal health service use: this referred to the extent of maternal health service use with her husband.

(3) Health service access included (1) Accessibility: this referred to the availability of MHS within reasonable reach of those who needed it including travel time to a health facility, road or transport link and public transportation. (2) Availability: this referred to the existing health services and good meets health consumer's needs. This study included resources in the health facility and time and (3) Affordability: referred to health consumer ability to pay for services without financial hardship to utilize MHS. This study also included cost (charges for maternal health service, drugs and supplies) and income (individual and family earning, reimbursement of transportation costs).

\section{Validity and reliability}

The questionnaire was developed and revised by reference books and knowledge of the theoretical background. The structured questionnaires were checked by three experts in family health, epidemiology and statistics to verify content validity and approved by a thesis advisory committee before the commencement of data collection.

For reliability, data had been collected from 30 mothers for the purpose of pre-test from a different area than the study sites. Additional editing to questionnaires was done according to the comments and responses from the pre-test. Overall Cronbach's Alpha Coefficient was 0.86 .

\section{Data processing and analysis}

Data analysis was conducted in SPSS 18 software. Before the data entry, raw data were checked for consistency and missing information. Descriptive and inferential statistics were used. For analysis of association univariate logistic regression was applied, and for predictor, multiple logistic regression was applied at $95 \% \mathrm{CI}$.

\section{Ethical consideration}

Ethical approval was obtained from the ethical review committee for human resources, Faculty of Public Health, Mahidol University (CAO. NO. 2019-53), and Nepal Health Research Council (NHRC) (Ref. no 3263). We obtained official permission later from the District Health Office Rolpa and Thawang rural municipality.

\section{Results \\ Descriptive results of research}

Among the 417 mothers participating in the study, just over half (50.84\%) completely used maternal health services which were greater than the district average. The research found that the use of maternal health services remains inequitable on many levels. This was particularly the case among women from disadvantaged caste ethnic groups (45\%), low age 
groups (43.1\%), illiterate groups (48.5\%) and housewives (48.9\%). A higher proportion of complete ANC utilization may reflect higher use of MHS, however, it does not indicate the quality of care received during those ANC visits.

Table 1 also shows the distribution of independent variables. Among the predisposing factors, most of the respondent were Hindu $(77.7 \%)$, a higher proportion were younger women living in the rural municipality $(<25$ years: $50.1 \%)$, more than half the mothers had not attained any formal education, whereas in the case of the husband's education, it was higher $(55 \%)$. The majority of the respondents had a high level of knowledge on maternal health $(67.9 \%)$. Similarly, half of the respondents had low levels of decision-making autonomy. About $80 \%$ of couples communicated with each other on MHS options during the pregnancy. Regarding financial control autonomy, only $21.3 \%$ of respondents had a high level of financial control autonomy. Research showed that more than two-fifths of mothers had high-level access $(43.9 \%)$ in the overall access index.

\section{Multivariable analysis}

Table 2 shows the result of univariate and multivariable logistic regression. In the univariate analysis, the age of the respondent, education level, and knowledge level of the respondent, all three dimensions of women's autonomy (decision-making, financial control and communication with a spouse), and all three dimensions of health service access (accessibility, availability and affordability) were significantly associated with the use of MHS.

Of the various predisposing factors, women's autonomy and health service access variables in multiple logistic analysis, age group of respondent $(\phi=0.043)$, spouse communication $(\phi<0.001)$, health accessibility $(\phi=0.007)$ and affordability $(\phi<0.001)$ were significant influencers in the use of MHS in the final model.

The research revealed that the age group of the respondent was the only predisposing variable that significantly influenced the use of MHS. Mothers from the 25-30 years age group were more than two times likely to have used MHS (AOR: 2.30; 95\% CI: 1.199-4.422) compared to younger mothers. Similarly, another influencing factor was communication with the husband; mothers who communicated with their husbands were 7 times more likely to use MHS (AOR: 7.31; 95\% CI: 2.574-20.791) compared to mothers that didn't.

In this research, mothers who had higher levels of physical accessibility to the service center were more likely to use MHS ( $p=0.007 ; 95 \%$ CI). Mothers who had high-level accessibility were two times more likely to use services compared to low-level accessibility. Similarly, affordability becomes another significant predictor $(\phi<0.001,95 \% \mathrm{CI})$. Mothers who had high affordability were ten times more likely to use MHS (AOR: 10.89; 95\% CI: 4.6625.445) compared to those with low affordability status.

\section{Discussion}

This research found that the proportion of mothers using MHS was just more than half $(50.84 \%)$ compared to the $69 \%$ nationwide average. Among all mothers of reproductive age, there were disparities among disadvantaged caste ethnic groups $(45 \%)$, young mothers $(43.1 \%)$, illiterate mothers $(48.5 \%)$, and housewives $(48.9 \%)$ in using MHS. However, such types of disparity are seen nationwide [5]. We found that the use of MHS was associated with a number of factors ranging from predisposing factors, women's autonomy and health service access.

Mothers from the higher age groups were more likely to use MHS. This is in contradiction to the finding of previous studies conducted in Nepal [28, 29], where in one study, these findings were well supported while in another study, trends of using MHS decreased with the increase in age of the respondent but there was no association. Possible reasons for the increased use of MHS in the 25-30 years group may be that they are more aware of the consequences of
Utilization of maternal health services 
JHR

36,1

146

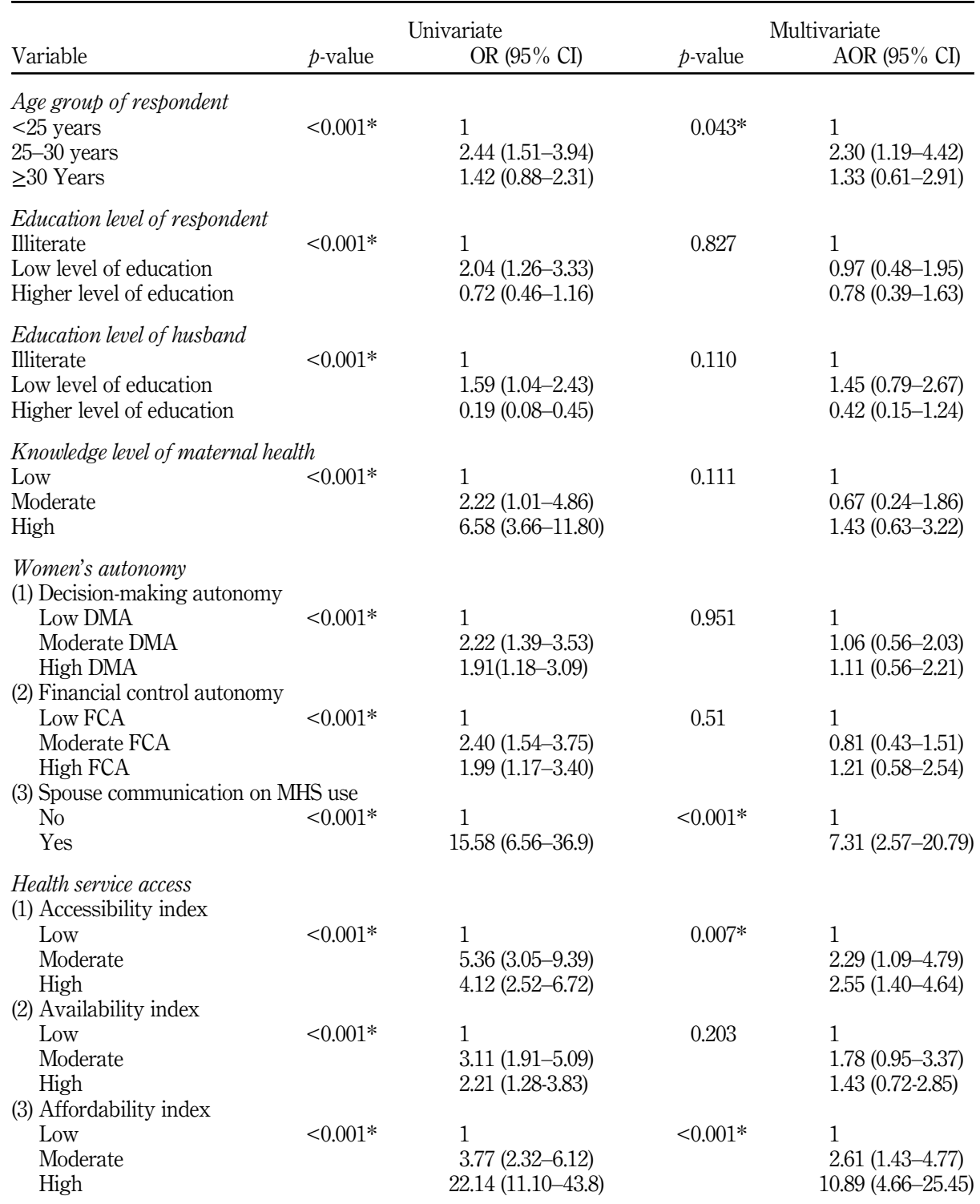

Table 2.

Logistic regression analysis
Note(s): $* p$-value $<0.05$

$* * * \mathrm{OR}=$ Odd ratio, $95 \% \mathrm{CI}=95 \%$ Confident Interval

adolescent pregnancy and have a higher decision-making capacity in the rural setting of Nepal compared to the past.

Surprisingly, this research suggests that the likelihood of use of MHS was 7 times greater when communicating with the husband about MHS during the pregnancy period. The previous study conducted by Shah et al. in Nepal showed an association between decision- 
making autonomy and outcome variables [21], and similar results were found by Ghose et al. in Bangladesh in 2017 [30]. It should be noted that the majority of the mothers in this research using MHS were those who made a joint decision with their husbands. Women whose husbands are involved in a discussion about pregnancy and the use of MHS can support the spouse to identify the appropriate health institution to visit, arrange transportation, and collect information in a rural setting that may lead to increased use of MHS.

This research showed that Availability and affordability were factors for the utilization of MHS. Mothers with moderate levels of accessibility were five times more likely to use MHS compared to mother experiencing low accessibility levels, and this was even more so, i.e. 22 times higher, in the high affordability subgroup compared to the low affordability subgroup. It should be noted that distance to the health facility, availability of health workers, and being able to afford the purchase of drugs and other health services had high utilization of maternal health services. The study conducted by Shah et al. and Chaurasiya et al. in Nepal also provides evidence to support an association between accessibility and use of MHS [21, 31]. Possible reasons may be due to poor transportation, the geographical distribution of settlements in hilly areas, and the same type of economic condition of people in rural Thawang. Another reason may be that in many wards of rural Rolpa, the birthing facilities in institutions were only built during the last two-three years and still had very poor physical infrastructure with few trained health workers.

\section{Strengths and limitations}

This research is not free from some methodological limitations, but equally, shows some important strengths. This was a community-based cross-sectional study, and like all crosssectional studies, it identifies the association of different factors with the use of maternal health services, but could not establish causal relationships. The research area was one of the rural areas of mid-western Nepal, Rolpa district, characterized by a relatively low percentage use of MHS compared to other districts and the nation, and this may limit the generalizability of results to other settings of the country. The research focused only on the consumer's perspective but not the provider's perspective and so, might not include all the factors responsible for use of maternal health services.

\section{Conclusions}

Use of maternal health service is a complex behavioral phenomenon. This research concluded that low coverage of these services is the result of socioeconomic barriers, poor access to health services, and other physical developments in such areas. To increase the utilization of MHS in rural areas, local health authorities and the community should tackle the root causes such as early marriage, increase female education and empowerment, and increase accessibility and affordability. This study recommends more in-depth research regarding access and quality of MHS in the public as well as the private sector.

Conflict of interest: There is no conflict of interest.

\section{References}

1. Alkema L, Chou D, Hogan D, Zhang SQ, Moller AB, Gemmill A, et al. Global, regional, and national levels and trends in maternal mortality between 1990 and 2015, with scenario-based projections to 2030: a systematic analysis by the UN Maternal Mortality Estimation Inter-Agency Group. Lancet. 2016; 387(10017): 462-74. doi: 10.1016/S0140-6736(15)00838-7.

2. United Nations [UN]. The millennium development goals report 2015. New York: UN; 2015.

3. Blencowe H, Cousens S, Jassir FB, Say L, Chou D, Mathers C, et al. National, regional, and worldwide estimates of stillbirth rates in 2015, with trends from 2000: a systematic analysis. Lancet Glob Health. 2016; 4(2): e98-e108. doi: 10.1016/S2214-109X(15)00275-2. 
JHR

36,1
4. World Health Organization [WHO]. United nations children's fund [UNICEF]; united nations population fund [UNFPA]; World bank group; united nations population division. Trends in maternal mortality: 1990 to 2015. Geneva: WHO; 2015.

5. Nepal, Ministry of Health and Population. Nepal demographic health survey report 2016. Kathmandu: Ministry of Health and Population; 2017.

6. Government of Nepal, National Planning Commission. Sustainable development goals 2016-2030: national (preliminary) report. Kathmandu: Government of Nepal, National Planning Commission; 2015.

7. Nepal, Department of Health Service, Family Health Division. Nepal maternal mortality and morbidity study 2008/2009. Kathmandu: Department of Health Service; 2009.

8. World Health Organization [WHO]. World health statistics 2018: monitoring health for the SDGs, sustainable development goals. Geneva: WHO; 2018.

9. Rooney C. Antenatal care and maternal health: how effective is it? A review of the evidence. [cited 2020 Jan ]. Available from: http://apps.who.int/iris/bitstream/10665/59954/1/WHO_MSM_92.4.pdf. $\% \mathrm{E} 2 \% 80 \% 8 \mathrm{E}$.

10. Shahjahan M, Chowdhury HA, Akter J, Afroz A, Rahman MM, Hafez MA. Factors associated with use of antenatal care services in a rural area of Bangladesh. South East Asia Journal of Public Health. 2012; 2(2): 61-6. doi: 10.3329/seajph.v2i2.15956.

11. Nyongesa C, Xu X, Hall JJ, Macharia WM, Yego F, Hall B. Factors influencing choice of skilled birth attendance at ANC: evidence from the Kenya demographic health survey. BMC Pregnancy Childbirth. 2018; 18(1): 88. doi: 10.1186/s12884-018-1727-z.

12. Nepal, Ministry of Health and Population, Department of Health Service. Annual report 2016/ 2017. Kathmandu: Department of Health Service; 2017.

13. Nepal, Department of Health Service, Family Health Division. National safe motherhood plan (2002-2017). Kathmandu: Department of Health Service; 2002.

14. Nepal, Ministry of Health and Population. Maternal and child health in Nepal: the effects of caste, ethnicity, and regional identity. Further analysis of the 2011 Nepal demographic and health survey. Kathmandu: Ministry of Health and Population; 2013.

15. Nepal, District Health Office Rolpa. District health report 2016-17. Nepal: District Health Office Rolpa; 2017.

16. Ahmed S, Creanga AA, Gillespie DG, Tsui AO. Economic status, education and empowerment: implications for maternal health service utilization in developing countries. PloS One. 2010; 5(6): e11190. doi: 10.1371/journal.pone.0011190.

17. Awasthi MS, Awasthi KR, Thapa HS, Saud B, Pradhan S, Khatry RA. Utilization of antenatal care services in Dalit communities in Gorkha, Nepal: a cross-sectional study. J Pregnancy. 2018; 2018: 3467308. doi: 10.1155/2018/3467308.

18. Bhatta DN, Aryal UR. Paternal factors and inequity associated with access to maternal health care service utilization in Nepal: a community based cross-sectional study. PloS One. 2015; 10(6): e0130380. doi: 10.1371/journal.pone.0130380.

19. Celik Y, Hotchkiss DR. The socio-economic determinants of maternal health care utilization in Turkey. Social Science and Medicine. 2000; 50(12): 1797-806. doi: 10.1016/s0277-9536(99)00418-9.

20. Woldemicael G, Tenkorang EY. Women's autonomy and maternal health-seeking behavior in Ethiopia. Matern Child Health J. 2010; 14(6): 988-98. doi: 10.1007/s10995-009-0535-5.

21. Shah R, Rehfuess EA, Maskey MK, Fischer R, Bhandari PB, Delius M. Factors affecting institutional delivery in rural Chitwan district of Nepal: a community-based cross-sectional study. BMC Pregnancy Childbirth. 2015; 15(1): 27. doi: 10.1186/s12884-015-0454-y.

22. Osamor PE, Grady C. Women's autonomy in health care decision-making in developing countries: a synthesis of the literature. Int J Womens Health. 2016; 8: 191-202. doi: 10.2147/IJWH. S105483. 
23. Andersen RM. Revisiting the behavioral model and access to medical care: does it matter?. J Health Soc Behav. 1995; 36(1): 1-10.

24. Perkins DD, Zimmerman MA. Empowerment theory, research, and application. Am J Community Psychol. 1995; 23(5): 569-79. doi: 10.1007/BF02506982.

25. Goverment of Nepal, National Planning Commission; United Nations Development Programme [UNDP]. Nepal human development report 2014: beyond geography, unlocking human potential. Kathmandu: Government of Nepal, National Planning Commission; 2014.

26. Lemeshow S, Hosmer DW Jr, Klar J, Lwanga SK. Adequacy of sample size in health studies. maternal health services Chichester: John Wiley \& Sons; 1990.

27. World Health Organization [WHO]. WHO antenatal care randomised trial: manual for the implementation of the new model. Geneva: WHO. 2002.

28. Mehata S, Paudel YR, Dariang M, Aryal KK, Lal BK, Khanal MN, et al. Trends and inequalities in use of maternal health care services in Nepal: strategy in the search for improvements. Biomed Res Int. 2017; 2017: 5079234. doi: 10.1155/2017/5079234.

29. Gautam S, Jeong HS. The role of women's autonomy and experience of intimate partner violence as a predictor of maternal healthcare service utilization in Nepal. Int J Environ Res Public Health. 2019; 16(5): 895. doi: 10.3390/ijerph16050895.

30. Ghose B, Feng D, Tang S, Yaya S, He Z, Udenigwe O, et al. Women's decision-making autonomy and utilisation of maternal healthcare services: results from the Bangladesh Demographic and Health Survey. BMJ open. 2017; 7(9): e017142. doi: 10.1136/bmjopen-2017-017142.

31. Chaurasiya SP, Pravana NK, Khanal V, Giri D. Two thirds of the most disadvantaged Dalit population of Nepal still do not deliver in health facilities despite impressive success in maternal health. PloS One. 2019; 14(6): e0217337. doi: 10.1371/journal.pone.0217337.

\section{Corresponding author}

Arpaporn Powwattana can be contacted at: arpaporn.pow@mahidol.ac.th

For instructions on how to order reprints of this article, please visit our website: 